Meta

Journal des traducteurs

Translators' Journal

\title{
The Sense of a Beginning: The Dynamics of Context in Translation
}

\section{Paul Samuel Di Virgilio}

Volume 29, numéro 2, juin 1984

URI : https://id.erudit.org/iderudit/004025ar

DOI : https://doi.org/10.7202/004025ar

Aller au sommaire du numéro

Éditeur(s)

Les Presses de l'Université de Montréal

ISSN

0026-0452 (imprimé)

1492-1421 (numérique)

Découvrir la revue

Citer cet article

Di Virgilio, P. S. (1984). The Sense of a Beginning: The Dynamics of Context in Translation. Meta, 29(2), 115-127. https://doi.org/10.7202/004025ar d'utilisation que vous pouvez consulter en ligne.

https://apropos.erudit.org/fr/usagers/politique-dutilisation/ 


\title{
THE SENSE OF A BEGINNING : THE DYNAMICS OF CONTEXT IN TRANSLATION
}

\author{
Paul Samuel Di Virgilio
}

Until recently, the theory of translation has done little to provide the translator, faced with any text not to mention a literary text, with a sense of a beginning. Nonetheless, the perspicacious comments of Milan Dimič in a discussion of the history of translation and the etymology of two sets of terms signifying translation over a 4000 year time span suggest a fruitful dichotomy in the quest for a sense of a beginning in the area of the pragmatics of translation (1975:14) :

The two words usually designating this process are translation and interpretation. Leaving aside for the purpose of this paper transformations from one representational system into another, we are left first of all with the act, process, or instance of translation, i.e., rendering from one (natural) language into another. In its intuitive way, well before philosophers and even poets, language itself has developed symbolic connotations within the words used to describe this activity. The English term and similar words in all Romance languages were developed from the Latin suppletive participle transferre, which means to translate, but also to transfer, to transpose, as if to transport from one shore of a river to another; the same applies to the German übersetzen and übersetzung (which Heidegger links with iberlieferung") as well as to the Russian perevodit and perevód (cf. e.g., perevesti na drugugy storonu ulicy). The Latin interpretatio first meant the explanation of what is not immediately plain or explicit (interpres iuris and interpres poetarum), reminding one of the Latin pretium (value), and therefore 'to give, explain value' and of the Greek herméneutikos, to interpret, to understand properly. As a result, the meaning in both languages became : the act or the result of translating from one language into another. This was initially used both for written and oral translation, the latter meaning dominating at least since the twelfth century. The German Dolmetscher (from the MHG tolmetze), the Russian tolmac, and the Hungarian tolmacs go back to the Osmanli Turkish tilmac; the English and French dragoman (drogman) to the Arabic tarduman, the old Arabic targoman, and this probably to the Aramic targum and Mitannic talami and to the Assyrian ragamy, all meaning "to interpret" but also simply to be able to talk.

This dichotomy is based upon the meaning of to interpret in the context of "dolmetschen" which is synonymous with the simple act of communication and the meaning of to interpret in the context of "hermēneutikos" meaning to give value, and to understand properly. Clearly, the initial act, "dolmetschen" is inherent in every sense of translation whereas translation as interpretation or value judgement will occur in translations where the context of the language valorizes the meaning of the text. Two great currents of thought have evolved from this dichotomy, dominating translation theory throughout its history : the activity designated in this study as "dolmetschen" has been popularized under the catch phrase "word for word" translation, whereas the meaning of interpretation, with all of its literary ramifications, is discussed largely in translation 
theory as meaning to meaning or "sense for sense" translation. The differentiation of the two modes is recognized by theoreticians discussing the two phenomena as a contextual distinction rooted in the first case in a strict adherence to formal aspects of the source language and in the second case rooted in a concern for a deep understanding of the meaning of the source culture text in a parallel context in the target culture. Although the catch phrases are often repeated, no more meaningful definition nor understanding of the two catch phrases is forthcoming from nineteenth and twentieth century theory than in the fragmented arguments inherited from Latin and earlier texts. An examination of the claims of authors to the use of "word for word" or "sense for sense" translation does little to clarify their basis for the distinction or to suggest a methodology for examining this distinction. It is difficult to understand in what sense Plautus and Terrence claim to have copied Greek models "word for word" after examining these "translations". Furthermore, Cicero's reasons for insisting that his translations are "sense for sense" were obscure when one tries to justify his claim by comparing his "sense for sense" translations with Terence and Plautus' "word for word" translations. The failure to perceive any clear distinction led, as is often the case, to the proliferation of hybrid terms in subsequent translation theory as a justification for the sometimes baffling distinction. Thus, translation gave birth to paraphrases, free translations, and copies as parody and plagiarism. The fragmentation of the subject into such specific categories does little to inform us of the basis for the original distinction between "word for word" and "sense for sense" translations. Neither the structure nor the evolution of these hybrids clarifies the two popularized categories nor offers the translator a sense of a beginning in addressing the source text. What has been inherited from the differentiation of "word for word" and "sense for sense" translation is a sense of a topology in which form and content suggest partial equivalences distinguishing the two modes of translation. It is the sense of a topology proposing equivalences which can serve as a point of departure in the translation process. In fact, it is George Steiner who suggests that a topology is the only acceptable model for equivalences in the theory of translation in After Babel (1975 : 425) :

The manifold transformations and reorderings of relations between an initial verbal event and subsequent reappearances of the event in other verbal or nonverbal forms might best be seen as topological. By that I mean something quite simple. Topology is the branch of mathematics which deals with those relations between points and those fundamental properties of a figure which remain invariant when that figure is bent out of shape...

The sense of a topology allows one to discuss not only the dichotomy based upon the differentiation of "word for word" and "sense for sense" translation but also the concept of transference from the source language to the target language. The area of equivalence is represented by the topology and not by the individual elements which make up the topology. Therefore, the success of a translation can be judged by neither equivalence of form nor content in isolation. The effect of equivalence in the topology is the generation not of a synonymy of form nor content, which seems to be impossible to realize, but rather the coincidence of form and content in a isomorphic ${ }^{1}$ relationship during the act of text-reception. Steiner's observation provides two new elements in

1. Isomorphic will be understood as the type of partial equivalence which guarantees only the stability of the topology not the equivalence of its constituent elements as R.R.K. Hartmann and F.C. Stork's definition of isomorphism in Dictionary of Language and Linguistics (New York: Wiley 1972) p. 120 sug. gests : 
translation theory, previously very seldom discussed, the possibility of an invariant topology with variable constituents combined with the sense of a permanent and shared constituent and for interpretation which will resolve the variables as an adequate invariable topology. This sense of reception is inherent in Peirce's tripartite sign combining three virtual elements representing signification, reference and interpretation as the sign, object and interpretant (1931-1935 : II, 228) :

A sign is anything which determines something else (its interpretant) to refer to an object to which itself refers (its object) in the same way, the interpretant becoming in turn a sign.

The topology suggested by the tripartite structure of Peirce's sign is the triangle which easily fulfills the requirements for Steiner's sense of a topology which is infinitely variable but at the same time essentially invariable. Thus, the relationships between the constituents can be described as approaching coincidence or maintaining the integrity of their separation by the variability of the distance between the three points and the resulting variation in angle. Such purely schematic devices have no linguistic reality of their own but allow us to more accurately and simply visualize complex relationships.

In consequence of the fact that all of the constituents of Peirce's sign are in themselves signs, the system is completely objective. This limitation indicates that the interpretant must not be confused with the speaker, receiver or linguistic community. In fact the tripartite sign is both synchronic and abstract enjoying no spatial nor temporal articulation with concrete phenomena. The synchronic relationships described by the proposed model are syntactic (the relation of sign to sign), semantic (the relationship of sign to object), and pragmatic (the relationship of the sign to the interpretant). Thus, the proposed model facilitates the comparison of both form and interrelationship of functions common to both source and target languages in a meaningful manner. The synchronic behaviour of this sign model borrowed essentially from the context of communication reflects an important difference between the speech act and translation which radically separates the two in spite of their shared attributes. The basic distinction is in the nature and the status of the interpretant : in the speech act the interpretant serves as the guarantee for the sens of "Verstehen" proposed by Gadamer as the basis for communication, whereas in translation the interpretant is the index of the alien status of the text as communication in the target culture $(1960: 363)$ :

Wo Verständigung ist, da wird nicht übersetzt, sondern gesprochen. Eine fremde Sprache verstehen bedeutet ja, sie nicht in die eigene Sprache übersetzen müssen. Wo einer eine Sprache wirklich beherrscht, bedarf es keiner Übersetzung mehr, ja erscheint jede Übersetzung möglich. Eine Sprache Verstehen is selbst noch gar kein wirkliches Verstehen und schliesst keinen Interpretationsvorgang ein, sondern ist ein Lebensvollzug. Denn eine Sprache versteht man, indem man in ihr lebt - ein Satz, der bekanntlich nicht nur für lebende, sondern sogar für tote Sprache gilt. Das hermeneutische Problem ist also kein Problem der richtigen Sprachbeherrschung, sondern der rechten Verständigung über die Sache, die im Medium der Sprache geschieht. Jede Sprache ist so erlernbar, dass ihr vollendeter Gebrauch einschliesst, dass man nicht mehr aus seiner Muttersprache oder in seine Muttersprache übersetzt, sondern in der fremden Sprachedenkt. Für die Verständidung im Gespräch ist solche Beherrschung der Sprache geradezu eine Vorbedingung. Jedes Gespräch macht die selbstverständliche Voraussetzung, dass die Redner die gleiche Sprache sprechen. Erst wo es möglich ist, sich durch das Miteinaderreden sprachlich zu verständigen, vermag das Verste-

ISOMORPHISM Similarities between two or more languages in their phonological grammatical or semantic structure. Even in genealogically related language families, complete isomorphism is non-existent, as every language has its own organisation of $\rightarrow$ meaning into $\rightarrow$ form, e.g. the vocabulary relating to colour and kinship concepts. Even from one stage in the historical development of a single language to the net the various structures are not isomorphous. (2.1. Lyons.) 
hen und die Verständigung überhaupt zum Problem zu werden. Das Angewiesensein auf die Übersetzung des Dolmetschers ist ein Extremfall, der den hermeneutischen Vorgang, das Gespräch, verdoppelt : es ist das des Dolmetschers mit der Gegenseite und das eigene mit dem Dolmetscher.

Therefore, although Peirce's sign provides a sense of a beginning and allows us to address ourselves to the source text in a pragmatic fashion, the topology in itself is incomplete as a means of judging the ultimate success of translation in as much as its failure to engage time and space refuses it access to the experiential domain of "Verstehen". Nontheless as Gadamer observes this type of activity responds to our historical distinction between "dolmetschen" and to interpret in the sense of "hermēneutikos".

By examining a single sign which poses conceptual problems, although its referentiality falls completely in the concrete sphere, one can perceive the relationship between the two processes and hopefully shed some light on a methodology for engaging the "dolmetschen" and interpretation in a coherent and complementary methodology. The sign which I have selected for this purpose is "chair". In the synchronic context of the speech act, the sign adheres to the process described by figure I :

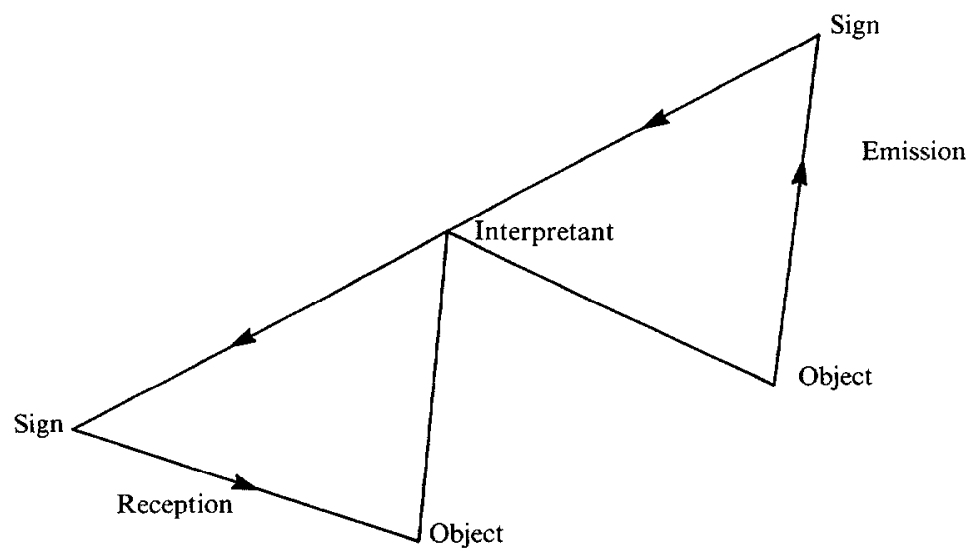

Figure I

In this process, the interpretant serves as a generalizing category for reducing the disparity between personal perception and the needs for universal accessibility within the linguistic community. This basic relationship establishes the principle of "sameness" that is to say the linguistic tendency to look for similarity through analogy disregarding the residual disparity in the model. This type of model building poses little problem within the closed system of the linguistic community, but in the comparative activity called translation the models fail as they rely upon the simplistic creation of categories to accommodate the preconceived "sameness". As Gadamer points out in translation the "Verstehen" or convention of "sameness" or "Verstehen" itself must be articulated in the translation as a sign of opacity not the guarantee of understanding. It is this need to deal with context and ultimately the science of epistemology in translation which determines the axis of articulation for elementary acts of interpretation and for more complex acts dealing with concepts of human knowledge. Not all the blame for this reduction of the translation process to a simplistic model can be laid at the linguist's doorstep, for Harris, a linguist himself, warns in Translation Propositions (1968:221) : 
Translation is often defined by linguists, unwarrantably, in terms of equivalence. For the linguistic analysis of translation, however, we need no guarantee that texts are equivalent, merely that they match and that the pattern of matching is, within certain limits, consistent. Not all kind of matchings are equivalences, and where there are equivalences, translation analysis must discover them, not assume them.

In fact, synonymy must be discarded as a valid and desirable phenomenon in translation, even if such a coincidence of thought is possible in the context of the speech act, because of the absence of the conventionality which Gadamer describes as "Verstehen" in the act of translation. Let us return to our elementary and apparently concrete sign, "chair" and examine its transformations in translation. Within the common linguistic environment of the European community, problems of contextual interference already become apparent as French and German demand greater precision in the exact concrete appearance and use of this object before affording the translator a linguistically and culturally appropriate equivalent for the English generic term, "chair". Thus, translation imposes an intersubjective evaluation on the use of language implied in each language system by the role of the interpretant. The increase or decrease of cognitive information necessary to make each interpretant role function distinguishes the activity of translation from speech within the linguistic community. The same process of accruement or diminution becomes more marked where cultural distances are greater. Consequently the translator, faced with the lexical unit "chair", is constrained to exploit a "sense for sense" process in translation where the target language stems from a culture where chair is absent as a concept and consequently not available as a lexical unit in any form. Furthermore, this process of comparative analysis in the interpretant can indicate that the concept is alien to the target culture or adapt the concept to cultural equivalents in the target language. Clearly, all of this activity surpasses the linguistic framework for the matching of signs and syntactic structures. An obvious example of a translation difficulty arising from our seemingly simple sign, "chair", is its entry into Oriental languages where the concept of seating is considerably different.

Although the elementary semiotic topology is common to every translation activity and serves adequately as a sense of a beginning it does not provide a focal point for the epistemological or intersubjective activity which must serve as the complement to mere linguistic matching in the absence of the guarantee of "Verstehen" as the interpretant's function. The deviation between the two interpretant signs becomes progressively more marked in the case of signs dealing with abstractions in as much as such signs only enjoy a conventional referentiality established by the linguistic community through the medium of their interpretant. Although the two processes inherent in the adequate translation of the simple sign, "chair" seem to coincide with the traditional distinction between "word for word" and "sense for sense" translation, the distinction neither informs us of the frontier of each activity nor of the deep structure setting each function in progress. In order to establish a threshold for each function, let us look to Mukarovsky's distinction between the dynamic and the static states of the sign and its relationship to hidden meaning as set forth in On Poetic Language.

Mukarovsky suggests a threshold for the distinction between the static and dynamic processes of the sign in "The Semantic Dynamics of Context" (1975:50):

The utterance is, therefore, a semantic stream which pulls individual words into its continuous flux, depriving them of a considerable part of their independence of reference and meaning. Every word in an utterance remains semantically 'open' up to the moment that the utterance ends. As long as the utterance flows, each of its words is accessible to additional shifts in its reference and to changes of meaning due to further context. It can hap- 
pen, for instance, that the initial emotional coloration of a word changes under this influence into its very opposite, that the meaning of the word subsequently contracts or expands, and so forth.

Hence a dynamic semantic unit differs from a static one by virtue of the fact that it occurs as a gradually realized context. The relationship between a static and a dynamic semantic unit, as is obvious, is reciprocal. A dynamic unit, being a mere semantic intention in itself, needs static units for its embodiment ; a static unit, on the contrary, acquires an immediate relation to reality only in a context.

From Mukarovsky's observations, one can conclude that the threshold for a shift to a "sense for sense" translation is recognized in the contextual demands of the text. The same contextual implications form the basis for the definition of the parameters for an epistemology in the philosophical context. The dynamics of the decoding and encoding of the contextual correlatives inherent in translation as an act of communication constitutes the basis for the hidden meaning which Mukarovsky attributes to the single communicative function, the subject in its role in the specification of all other textual functions $(1975: 60)$ :

Nevertheless, monologue and dialogue are more than a mere functional languages, for the monologic or dialogic nature of a linguistic utterance is determined by whether the utterance comes from one or more subjects. The application of any of the other functional languages is, however, determined by the decision of only one subject. Therefore, the difference between monologue and dialogue is more basic than the other differences among functional languages ; this is also apparent from the fact that each of the participants in a dialogue can employ a different functional style. Thus functional differentiation appears to be a secondary superstructure with regard to the difference between monologue and dialogue.

The necessity of considering two subjects' relationship to the production of a text during the act of translation points to the need for an expanded frame of reference for the consideration of a translation's success. A second axis is needed to express the diachronic tension inherent in the translation's ontological status as the product of a first and second or subsequent articulation. Consequentiy, the problems of equivalence are complicated by the separation inherent in the double articulation of the translation. Thus two structures must be matched : first, the linguistic structures implied by the three principal elements in the semiotic topology, and secondly, if the contextual correlatives inherent in the interpretant function in each language system fail to coincide in any significant manner, the interpretants themselves in reference to an intersubjective process with both temporal and spatial contexts based upon the cultural and epistemological data supplied by each linguistic community as metalanguage. Thus, the first articulation of the translation as invariant core or semiotic topology is transferred as such from one linguistic community to the other varying only the relationship between the constituent parts not the actual topology itself.

However, the invariant core is corrected in the perceptual dimensions of time and space in a second articulation based upon the cultural data supplied. The second articulation determines the shape of the invariant core itself in the shared topology of the translation. It is undoubtedly in this field where most modern translators go astray although contemporary theory of translation is acutely aware of the problem ${ }^{2}$. The failure of the translation to respect the source's text's contextual integrity can be recog-

2. Gideon Toury discusses this contextual problem extensively in "The Nature and Role of Norms in Literary Translation", Literature and Translation (Leuven : Acco, 1978), pp. 83-100. 
nized by a lack of coincidence in the interpretant signs. This failure to coincide is possible because the interpretant functions as an abstract code within each language system ignoring the problems of actualization of the communication in the interpersonal context. Within the linguistic community, the concerns of time and space are negated by the interpretant's functioning as "Verstehen", whereas in the context of the translation straddling two linguistic communities the diachronic tensions of the double articulation are emphasized. The adjustment and transformation in the variables of the invariant code can be understood as a semiosis introducing the intersubjective concerns of time, space and identity into the target culture. In "Sign Concepts, Semiosis and Meaning", J $\phi$ rgen Dines Johansen suggests the scheme in figure II as the basis for semiosis which I modify in figure III to arrive at a scheme reflecting time, space and identity in an intersubjective topology suitable for translation purposes $(1978: 161)$ :

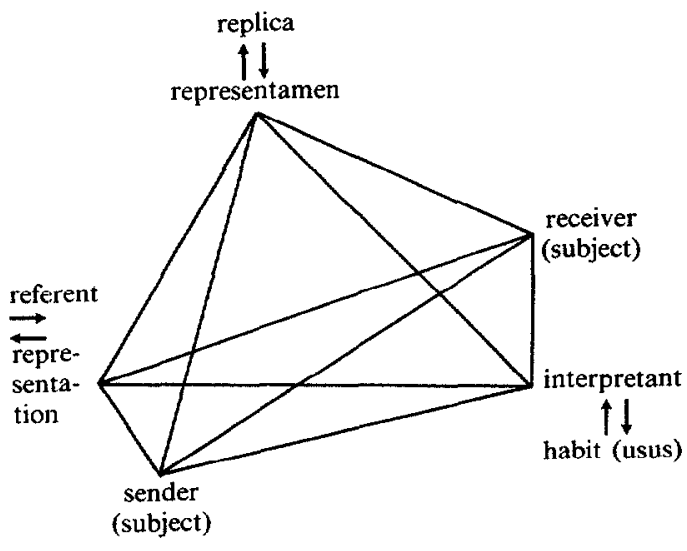

Figure II

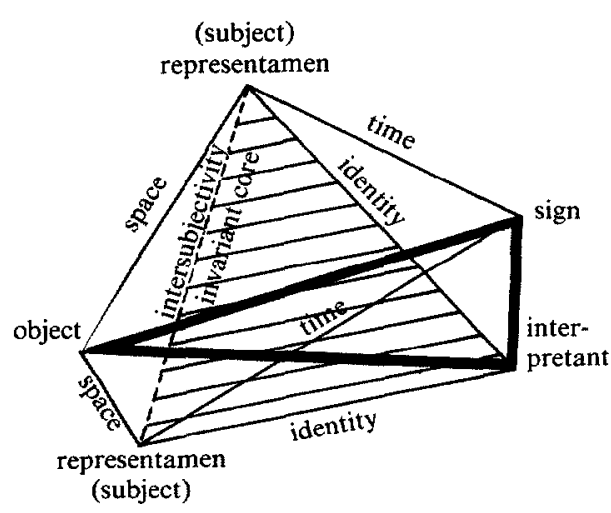

Figure III

The additional axis allows the actualized subject as cultural representamen to be compared to the corresponding cultural representamen in the target culture in reference to the phenomenal relationship between text, subtext, time, space and identity. The temporal and spatial latitude of the actualized model allows the translator not only the sense of a beginning but also a point of reference for comparison between the lexical corpus available in the source and target languages.

As is the case for any pragmatic model, the proof of its usefulness must be tested in the empirical field of intersubjectivity. Therefore it is the intention of this study to test the model against several traditional problems in translation theory as a means of verifying its efficacity. The broadest problem encompassed by this model is the definition of the specificity of signs as they occur in a context. All signs enjoy to a greater or lesser extent the same ability to shift their meaning in terms of their contextual environment as the sign presented as an elementary example, "chair". During the $10^{\text {th }}$ Congress of the International Association for Comparative Literature in New York during 1982, Wolfram Wilss suggested in a Translation Workshop that texts could be classified as Specific Language Practice texts and Nonspecific Language Practice texts. The basis for the 
distinction is not lexical but functional and contextual. The text practice and consequently the interpretant function of its signs is determined by the context of the textual discourse not by signs in their isolated occurrences. As a sign, the first level of meaning of which a sign such as "chair" avails itself registers as a zero level of articulation coinciding with the act of "Verstehen". Such an articulation must be considered as a nonspecific language practice and considered to be the basis for the theory of "word for word" translation. In languages where there exists a strong lexical, and syntactical similarity the distinction between the subjective representamen in the source culture, and in the target culture is minimized, creating the impression that the act of translation coincides with the elementary act of communication within the confines of the single plane of the semiotic sign. Abstract concepts or those which are culturally bound enjoy a deferral between the source and target representamens such as was noted in the relationship of "chair" to non-chair oriented cultures. The space of the deferral must be supplemented in order to assure the communication by a secondary information or accommodation of the meaning in the source language to an adequate equivalent in the target language. The second degree of articulation is sensed immediately in the transfer of lexical units with abstract meanings because such concepts, as has already been observed, depend heavily upon the interpretant function of the sign for their meaning with only a weak objective relationship. The deferrals generate an axis in reference to the semiotic topology as a whole in terms of its capacity to express the subjective representamen in the source and target languages. This intersubjective structure linking the form of the text to its actualization in a precise temporal and spatial context can best be understood as the equivalent of what Anton Popovic calls the "invariant core" in Dictionary for the Analysis of Literary Translation (1976 : 11) :

The invariant core is represented by stable, basic and constant semantic elements in the text. Their existence can be proved by an experimental semantic condensation. This core of standardized meanings makes a reader's or translator's ... concretization, i.e. transformations or variant, possible. These imply changes that do not modify the core of meanings but influence only the expressive form.

A problem, often discussed but never resolved in any coherent manner in translation theory is related to the status and the specific threshold of "literariness" in both the source and target languages. The source and target cultures function within the contours of Popovic's invariant core. In the context of topological transformation, "literariness" represents a single instance in the broader category of specific language practice is more readily approachable than the specific category of "literariness" because it is less marked by assumptions arising from prior discussion of the subject. Specific language practices are not encoded in the interpretant itself but rather in the substructure of that which Peirce calls the sign within his tripartite semiotic sign. It is the Danish semanticist, Hjelmslev who provides insight into the substructure of this element of Peirce's concept. Hjelmslev's format for the sign allows one to separate form and content within the elementary perception of the sign in such a way that the elements distinguishing specific language practices from nonspecific language practices or the linguistic sign proper can be addressed as meaningful units. The distributional problem is not lexical nor referential but rather functional as is reflected in the fact that the same lexical unit can function both in specific and nonspecific language practices with distinct semantic values in each case. Undoubtedly, the failure to recognize such contextual aspects of the interpretant's role in the linguistic community contributes to the greatest number of misunderstandings and translation distorsions in contemporary translations. Hjelmslev 
expresses this concept of the sign most concisely in "Pour une sémantique structurale" $(1970: 106)$ :

La fonction décisive est la commutation, ou la corrélation qui contracte une relation avec une corrélation du plan opposé de la langue. Deux membres d'un paradigme appartenant au plan de l'expression (ou au signifiant) sont dits commutables (ou invariants) si le remplacement de l'un de ces membres par un autre peut entrainer un remplacement analogue dans le plan du contenu (ou dans le signifié); et inversement...

Schematically this brief statement by Hjelmslev is generally represented in the following format suggested by Johansen $(1978: 145)$ :

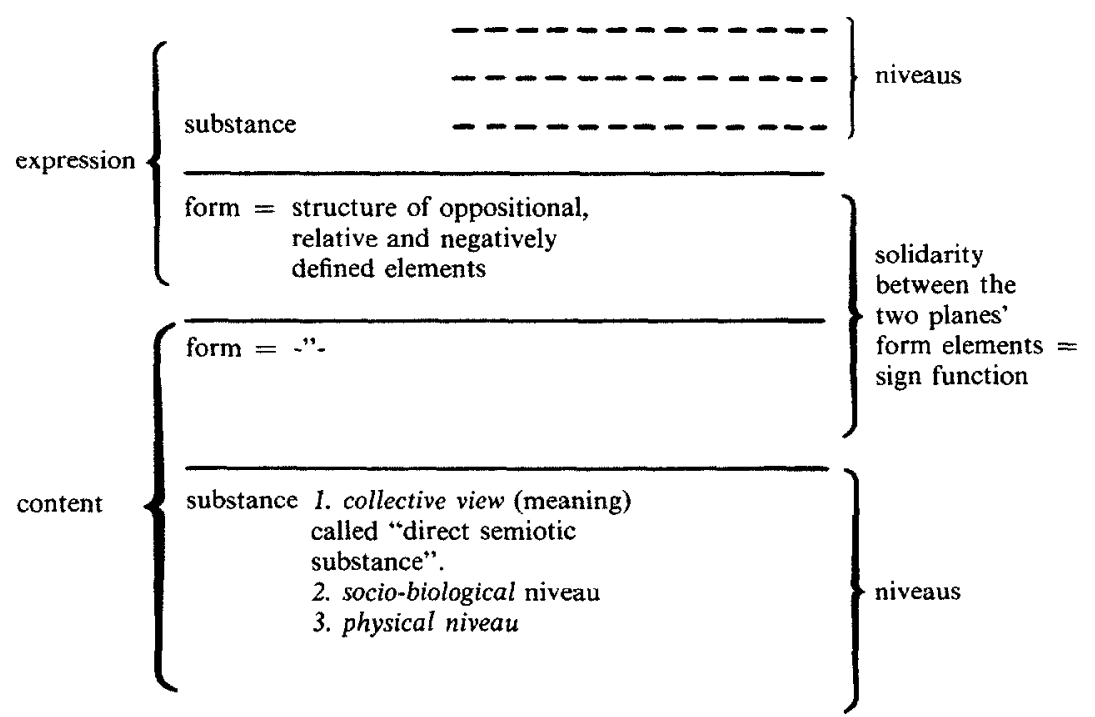

As Peirce's semiotic sign does not surpass the strictly formal context of semiotics, so Hjelmslev limits the range of language to formal concerns indicating that the residual effects of substance fall outside of the concerns of language. The determination of specific language practices and the formation of an invariant core is deferred to this supplemental and complementary area of language often called metalanguage although it would appear that at least half of its activity is sublinguistic. The niveaus or levels of practice are the locus of an intersubjective decision made as Mukarovsky observes exclusively by the speaker in his role as subject. The intersubjective decision is made regarding the discursive level and the specificity of the discourse which serve as the context for the assembled signs. In short, a scientific text, as a specific language practice, is governed by the same type of discursive contraints as a literary text. In general, the recessive trait, substance of content is marked as a discursive system in the specific language practice and thus a complement is added to the linguistic value of the signs which appear in the sequence marked by this text. An example of this interaction is the occurrence of the expression "if and only if" neither contains any scientifically marked lexical unit nor depends upon any exceptional syntactical combination. Nonetheless, in the context of a scientific or mathematical text, the expression is recognized as a syntagmatic unit with marked meaning in a narrower range than the sum total of its semantic values as perceived in a conventional communication functioning within the limits of the contraints imposed by the speech act. The repeated occurrence of such syntagmatic 
units alerts the receiver and the translator to the closed system within which the text is functioning, that is to say that the information communicated surpasses the face value of the signs deferring their ultimate interpretation to an integration function of the whole text in its role as discourse. By means of this integrating function which is outside of the parameters for the informal concerns of the sign, specific language practice texts inform us of their intentions and subsequently generate a discourse based upon the intersubjective residue not anticipated in the purely linguistic functions of the sign. The implications of this system are clear for the translator, for no matter which sign must be used to achieve this effect it is this invariant core which determines the decision making process in the semantic, syntagmatic and pragmatic relations between the constituents of Peirce's tripartite sign.

"Literariness" or rather the recognition of "literariness" depends upon a similar discursive transformation. Whenever the substance of the expression is marked that is to say in occurrences such as the literary usage of the trope, not only is a separative from the norm for linguistic behavior perceived but this separation is also referred or deferred to the specific language practice discourse discussed as the general principle for the resolution of problems arising from specific language practices in the preceding analysis of the scientific text. Consequently, the literary text is indexed as a discursive text in which the substance of the expression serves as the index or the mark of its discourse. Ivan Fonagy presents this concept of discourse in la Métaphore en phonétique dealing with the symbolic meaning assumed by phonemes as individual and immediate phenomena in the semantic and syntactical sequence of the text. Clearly, the recognition of this meaning responds to the concerns of many translators regarding the occurrence of specific sequences or of an abnormal emphasis on sequences of sounds by prose texts which contribute to the signification of the sign system in the reception of the text. In short such sequences, because they are significant, are also discursive and communicate information beyond the range of the discourse inherent in any dialogue based upon "Verstehen". Thus one can draw the following conclusions from these textual phenomena : the text exploiting nonspecific language practices represents a first degree of contextuality resolved in the relationships proposed by Peirce's semiotic model of the sign, whereas specific language practice texts such as scientific or mathematical texts enjoy a deferral to a second articulation in a context governed by discourse and not properly belonging to the context of the linguistic sign. In the discursive articulation the intersubjective residue of the linguistic sign generates a mythic space in which the sense of an invariant core results from meaning shared by texts related to a common archetypical discourse. However, the contextuality of a second articulation does not exhaust the possibilities of the "literariness" in its archetypal models. The literary text provides examples of articulations to the third degree in as much as the problem posed by specific formal practice (many literary effects resulting from phonetic or syntactical peculiarities) are referred or deferred to the context of the second degree for resolution that is to say to the discursiveness of the specific language practice. If each degree of articulation is understood as a context, each degree of articulation must also represent an elaboration of the role of Peirce's interpretant in reference to the invariant core based upon the intersubjective verification of the text's archetypal meaning by a member of the source and target languages, often coinciding in the translator. This joint identify forms the basis for what Anton Popovic (1976 : 30) defines as a metatext :

Metatext : the model of prototext : the way of realization of intertextual invariant between the two texts. The rules of this modelling are the textformating activity generated by the creator of metatext. 
The simplistic objective model resulting from a purely semiotic approach to the problems of translation and textual specificity serves to initiate the resolution of major structural differences between texts both in relationships isolated in a single source language and in relationships implying a source and a target language by providing a clearly defined topology for the comparison of these differences. When shifts are necessary in the metatext where the focal point of a minimal syntactical unit such as the sentence is radically different in the source and the target languages, the intersubjective relationship serves as a context for the transformation of the interpretant sign, informing the translator of the acceptable limits for these transformations in the target language. Of course the same process is inherent in the act of reading or interpretation and it is for this reason that the productivity of such activities cannot be successfully described in the limited framework of speech act theory with its dependence upon a single articulation. As an example of such a radical shift let us anticipate the transit of an Oriental text where the syntactical subject plays a peripheral role in the sentence to a Western language such as English where the syntactical subject plays a central role in the decoding of the communication. The successful translation and interpretation will have to elaborate a system within the context of the interpretant capable of suggesting that the source language did not recognize the syntactical subject as the focal point for the hermeneutic and intersubjective process of communication. Thus, the translator working within the English system must face the impossible question : What do I say if I don't say "I" ? The answer must be arrived at pragmatically through a decision making process which Jiři Levý accurately describes as follows in "Translation as Decision" (1967: 1179) :

As all semiotic processes, translation has its PRAGMATIC DIMENSION as well ... Translation theory tends to be normative, to instruct translators on the OPTIMAL solution : actual translation work, however, is pragmatic ; the translator resolves for that one of the possible solutions which promises a maximum of effect with a minimum of effort. That is to say, he intuitively resolves for the so-called MINIMAX STRATEGY.

In fact the decision making process leads the translator towards the recognition and exploitation of the archetypal possibilities of the second articulation which C. Stevenson presents as "megatype" in an attempt to explore a system for comparing two Peircian tokens in "On what's a Poem ?" (1957: 337) :

Two tokens will belong to the same megatype if and only if they have approximately the same meaning; so it is not necessary that the tokens belong to the same language or that they have that similarity in shape and sound that makes them belong to the same type. Thus any token of "table" and any token of "mensa", though not of the same type, will nevertheless be of the same megatype.

The coincidence of Stevenson's megatype with Steiner's isomorphic topology and Popovic's invariant core is not accidental but rather the product of the pragmatics of the decision making process put forth by Jiři Levý. In fact the resolution of the problem introduced at the outset of this study, the relationship of "word for word" to "sense for sense" translation cannot be contemplated in a theoretical framework but rather must be viewed in a pragmatic context. Therefore, the relationship is not simply a question of principles but rather the consequence of the actualization of transformations necessary to transfer texts from source to target languages. The sense of context and articulation which has evolved during the course of this study suggests the pragmatics of actualizing a text in an alien culture. Consequently, the sense of a beginning matching semiotic signs in the context of "Verstehen" is greatly removed from the sense of a finished trans- 
lation in which the equivalences will be based upon the interaction of texts through the medium of a megatype or invariant core. Therefore, one can conclude that the translator's work is dependent not upon perception but upon observation in Karl Popper's sense of the distinction made in "The Logic of Scientific Discovery" (1972:342) :

In science it is observation rather than perception which plays the decisive part. But observation is a process in which we play an intensively active part. An observation is a perception, but one which is planned and prepared.

Undoubtedly the sense of insight experienced in translation and interpretation in general results from our experience of what Levý calls the MINIMAX STRATEGY in the discovery of the megatype linking the epistemologies of the source and target cultures. Thus at some point all successful and enduring translations must address themselves to the "hidden meaning" of the "hermeneutikos" residing as a shadow on the caves of our cognitive faculties and guaranteeing our ultimate understanding of each other in translation.

Out of this recognition of a second knowledge it is possible to extrapolate the true meaning of the distinction between "word for word" and "sense for sense" translation. The former confines itself to the relationships of the semiotic model and behaves as though it were functionning in the context of "Verstehen" that is to say within the limits of the speech act. The activity of a "sense for sense" translation becomes evident when the first articulation is insufficient for the modification of the text in its transposition from source to target culture. Reference to second and third degree articulations surpasses the formal limits of the sign as Hjelmslev's model reveals putting us in the range of meta- and sublanguages. The consciousness of this manipulation of meaning with no distinct and determinate form of its own constitutes the basis for a "sense for sense" translation. "Word for word" translations function in the same synchronic space as speech and express readily the information contained within the signs in the source text. "Sense for sense" translation establishes a permanent mode of dialogue between the target culture and the source culture through the residual comparative epistemology resulting from the exploration of the second and third levels of articulation in communication. The activity of "sense for sense" translation is ambitious but not impossible as the great literary texts of various civilizations attest in the dialogue which they maintain between distant times and distant places, modifying, elaborating and illuminating each others' literary canons and epistemological assumptions. Consequently, each "sense for sense" translation has as its entelechy a "co-text" and a context serving to establish a greater dialogue linking not only the isolated text and its translation but also the canon itself, the whole network of texts serving as the basis for its expression and culture, with those of the target culture.

\section{REFERENCES}

DIMIČ, Milan (1975) : "Translation and Interpretation in Bicultural and Multicultural Societies", Translation and Interpretation: The Multicultural Context Symposium, Carleton University, pp. 13-34. GADAMER, Hans-Georg (1960) : "Sprache als Medium der Hermeneutischen Erfahrung", Wahrheit und Methode. Grundzüge einer philosophischen Hermeneutik, Tübingen, J.C.B. Mohr, pp. 361-367.

HARRIS, Roy (1968) : "Translation Propositions", Linguistica Antverpiensa, 2, pp. 217-227.

HJELMSLEV, Louis (1957) : "Pour une sémantique structurale", printed in : Hjelmslev : Essais linguistiques, Copenhagen, 1970 ed.

JOHANSEN, Jфrgen Dines (1978) : "Sign Concepts/Semiosis/Meaning", Orbis Litterarum, 4, pp. 123-176.

LEVÝ, Jiři (1967) : "Translation as a Decision Process", To Honor Roman Jacobson, III, pp. 1171-1182, The Hague, Mouton. 
MUKAROVSKY, Jan (1975) : On Poetic Language (edit by John Burband \& Peter Steiner), New Haven, Yale University Press.

PEIRCE, Charles S. (1931-1935) : Collected Papers, Cambridge, Mass., Harvard University Press.

POPOVIC, Anton (1976) : Dictionary for the Analysis of Literary Translation, Edmonton, Alberta, Dept. of Comparative Literature, University of Alberta.

POPPER, Karl R. (1972) : The Logic of Scientific Discovery, London, Hutchinson.

STEINER, George (1975) : After Babel : Aspects of Language and of Translation, London, Oxford University Press.

STEVENSON, Charles L. (1957) : "On What's a Poem ?", Philosophical Review, 66, pp. 329-363. 